\title{
Access to food source and food source use are associated with healthy and unhealthy food-purchasing behaviours among low-income African-American adults in Baltimore City
}

\author{
Heather D'Angelo ${ }^{1, *}+$, Sonali Suratkar ${ }^{2}$, Hee-Jung Song ${ }^{2}$, Elizabeth Stauffer ${ }^{3, \dagger}$ \\ and Joel Gittelsohn ${ }^{2}$ \\ 'Department of Health Behavior and Health Education, Gillings School of Global Public Health, University of \\ North Carolina at Chapel Hill, Chapel Hill, NC 27599-7440, USA: ${ }^{2}$ Department of International Health, \\ Center for Human Nutrition, Bloomberg School of Public Health, Johns Hopkins University, Baltimore, MD, USA: \\ ${ }^{3}$ Department of Physical Therapy and Rehabilitation Science, University of Maryland School of Medicine, \\ Baltimore, MD, USA
}

Submitted 21 April 2010: Accepted 5 February 2011: First published online 31 March 2011

\begin{abstract}
Objective: Although previous research has shown limited availability of healthy food in low-income urban neighbourhoods, the association between food source use and food-purchasing patterns has not yet been examined. We explored foodpurchasing patterns in the context of food source use and food source access factors in low-income areas of Baltimore City.

Design: Cross-sectional survey.

Setting: Predominantly low-income neighbourhoods in East and West Baltimore City. Subjects: A total of 175 low-income African-American adult residents.

Results: Supermarkets and corner stores were the most frequently used food sources. Walking was the main form of transportation used by $57 \%$ of all respondents, $97 \%$ of corner-store shoppers and $49 \%$ of supermarket shoppers. Multiple linear regression models adjusting for demographic factors, type of food source used and transportation type found that corner-store use was associated with obtaining more unhealthy food $(P=0 \cdot 005)$, whereas driving to the food source was associated with obtaining more healthy food $(P=0 \cdot 012)$.

Conclusions: The large number of corner stores compared with supermarkets in lowincome neighbourhoods makes them an easily accessible and frequently used food source for many people. Interventions to increase the availability and promotion of healthy food in highly accessed corner stores in low-income neighbourhoods are needed. Increased access to transportation may also lead to the use of food sources beyond the corner store, and to increased healthy food purchasing.
\end{abstract}

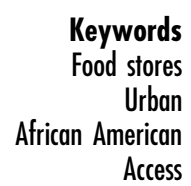

Minority populations in the USA are disproportionately affected by high rates of obesity and chronic diseases ${ }^{(1-4)}$. Previous studies have examined the association between dietary intake, obesity and the availability of food stores in low-income urban neighbourhoods ${ }^{(5-11)}$. Low-income urban minority neighbourhoods have fewer supermarkets, lower availability of healthy foods and greater availability of high-energy foods at fast-food restaurants than do middleincome, white and racially mixed neighbourhoods ${ }^{(5,7,11-16)}$. A large supermarket in an urban neighbourhood tends to increase fruit and vegetable intakes among residents,

\footnotetext{
$\uparrow$ The present study was conducted at the Department of International Health, Centre for Human Nutrition, Bloomberg School of Public Health, Johns Hopkins University. H.D.A. and E.S. were affiliated with this institution at the time of the study
}

whereas the presence of a convenience store tends to decrease fruit and vegetable intakes ${ }^{(6,10)}$.

Limited availability of healthy food has been associated with a less healthy diet, and living in a neighbourhood with a high density of fast-food restaurants may increase the likelihood of becoming obese, especially among people without cars ${ }^{(17-19)}$. In Baltimore City, the availability of healthy food is lower in predominantly AfricanAmerican (AA), low-income neighbourhoods compared with white higher-income neighbourhoods ${ }^{(20,21)}$. Further, a large number of neighbourhood fast-food and carry-out restaurants have been associated with higher fat intake and lower vegetable intake among $\mathrm{AA}^{(20,22)}$.

Although numerous studies have shown that there is less access to healthy food in low-income urban neighbourhoods, most studies limit access to the presence or 
absence of a store within a geographical area and have not assessed the impact on food-purchasing patterns ${ }^{(5)}$. In reality, food source use may be determined by the type of transportation available, length of travel time to the food source and personal reasons for preferring one food source over another. These same factors may impact the frequency of food source use and food-purchasing patterns. Access to transportation is important for residents of neighbourhoods with limited availability of healthy food, and may represent a significant barrier to purchasing healthy food. One study among low-income urban women in Minnesota found that both store location and access to transportation were major determinants of where the women shopped ${ }^{(23)}$. However, little is known about the influence of transportation access and length of travel time to the food store on food-purchasing patterns.

The present study reports on the baseline survey results of a store-based nutritional intervention targeted at lowincome AA. The purpose of the present study was to examine the associations of the type of food source used, the reasons for choosing a food source and food source access with patterns of obtaining healthy and unhealthy food in a low-income urban setting. In the present study, 'access' refers to the type of transportation taken to a food source, length of travel time to the food source and frequency of food source use. We use the term 'food source' as opposed to 'food outlet' because we have assessed not only the places where food can be bought but also sources of food obtained for free, such as from family or from a food pantry. Likewise, the term 'food getting' used in the present study refers to obtaining food from all sources either by purchasing, obtaining for free or using food assistance.

We address the following questions:

1. What types of food sources are used most often by low-income AA in urban neighbourhoods?

2. Why are these food sources selected?

3. What forms of transportation are used and what is the duration of travel to food sources?

4. How frequent are shopping trips to food sources?

5. How do access and food source choice relate to the frequency of obtaining healthy and unhealthy food?

\section{Methods}

\section{Study setting}

In 2008, $63.6 \%$ of the population in Baltimore City was $\mathrm{AA}^{(24)}$. In 2000, the median household income was \$US 30078 and $42 \cdot 8 \%$ of households earned < $<$ US $25000 /$ year ${ }^{(25)}$. In Baltimore City, $35 \%$ of adults are obese, compared with $26 \%$ for all of Maryland, and $12 \%$ of adults have diagnosed diabetes ${ }^{(3,26)}$. The study was conducted in East and West Baltimore, two primarily lowincome areas of the city. Baltimore City has a variety of food sources, the majority of which are small-to-mediumsized food stores, such as small supermarkets or corner stores, carry-outs and fast-food restaurants ${ }^{(21)}$. Lowincome areas of the city tend to have limited access to large supermarkets and limited availability of healthy food, such as fresh fruit and vegetables and low-fat milk $^{(20,21)}$. Formative research in this population showed high intakes of sweetened beverages and high-fat foods and low fruit and vegetable intakes ${ }^{(27)}$.

According to a 2005 report, $32 \%$ of Baltimore City residents do not have access to a car, a rate higher even than in New Orleans right before Hurricane Katrina $(26 \%)^{(28,29)}$. In formative research, residents of East Baltimore cited poor public transportation, lack of a car and increased travel time as major barriers in travelling to large supermarkets located outside their neighbourhoods ${ }^{(21)}$.

\section{Sampling}

Between April and November 2005, 175 AA respondents were recruited as a convenience sample from supermarkets, corner stores and community action centres in East and West Baltimore. Eligibility included: being a current resident of East or West Baltimore neighbourhoods; intending to be in residence for the next 12-18 months; being the main food preparer and shopper of their household; and, if female, not being pregnant and not having a child younger than 6 months. Women who were pregnant or had a child $<6$ months of age were excluded because of the assumption that their nutritional needs would impact their diet and therefore their foodpurchasing patterns. The study was approved by the Johns Hopkins Bloomberg School of Public Health Institutional Review Board.

\section{Measures}

The 106-item Consumer Impact Questionnaire (CIQ) used in the present study has been described in detail elsewhere ${ }^{(30)}$. The CIQ includes items to measure food source use, food source access and food getting, described in detail below. The CIQ also measured demographic information and items used to create a material style of life scale (MSL). The MSL scale assessed ownership of fourteen different items (e.g. television, cellular phone, central air conditioning) and was used as a proxy for socio-economic status (SES). A high MSL score approximates higher $\mathrm{SES}^{(30)}$.

\section{Food source}

Determination of the food sources used was based on responses to the open-ended question 'Which are the two places where you most frequently get food for your household?'. Food sources were categorized as supermarket (e.g. chain, including large- and medium-size supermarkets), corner store (e.g. small food store), carry-out/ fast-food restaurant, indoor/outdoor market, wholesale club, family/friends and shelter/food pantry according to 
the name, description and classification of the food source given by the participant (e.g. 'Jo's Market (corner store)' was coded as corner store). If the participant's description of the food source was unclear, name recognition, an in-person visit and an Internet search were used to classify the food source. In the present study, supermarket shoppers are those who indicated their first choice of food store as a supermarket; corner-store shoppers are those who indicated corner stores as their first choice. In order to compare food-getting patterns among supermarket and corner-store shoppers, all other food sources were grouped together as 'other', thus creating three categories.

The reason for shopping at a food source was measured by asking respondents to choose the main reason for shopping at their main food source from the following options: (i) better quality of foods; (ii) greater variety of foods; (iii) cleanliness and good service; (iv) convenience (close to home/workplace, accessible by public transportation); and (v) lower cost. Respondents were free to name more than one of the reasons listed, or name other reasons.

\section{Access factors}

Transportation mode was determined by asking respondents how they usually get to their most frequent food source, given a choice of: taking their own car, asking a friend or relative to drive, taking public transportation (specifying either bus, light rail or metro), paying for a cab or a hack (unlicenced cab) or walking. To reduce the number of categories of transportation used in ANOVA analyses and to account for small sample sizes in some categories, similar types of transportation were consolidated (e.g. cab and hack; bus and metro; driving and getting a ride).

Travel time was measured by asking respondents to report the length of time it takes to get to their most frequented food source from their homes. Shopping frequency was measured by asking respondents to report how often they use their main food source, given a choice of: every day, 5-6 times/week, 3-4 times/week, 1-2 times/week, 1 time/ 2 weeks, 1 time/month, only when it is the season or a few times a year.

\section{Food-getting scores}

The CIQ measured the frequency of obtaining a number of different foods, which includes getting food from all sources either by purchasing, getting for free or by using food assistance. These items were used to create the outcome variables: healthy and unhealthy food-getting scores. Healthy food-getting score summed the frequency of obtaining twenty-six healthy foods (e.g. low-fat milk, diet soda, fruit and vegetables, whole-wheat bread, highfibre and low-sugar cereals, low-sodium pretzels and cooking spray) in the past $30 \mathrm{~d}$. Sum scores ranged from 1 to 145 , with a mean of $34 \cdot 1(\mathrm{SD}=27 \cdot 2, \alpha=0 \cdot 77)^{(30)}$.
Unhealthy food-getting score was the sum of frequency of obtaining nine unhealthy foods high in fat and/or sugar (e.g. potato chips, soda, sugary drinks, whole milk and canned tuna in oil). Sum scores ranged from 0 to 147 , with a mean of $28 \cdot 4(\mathrm{SD}=26 \cdot 1, \alpha=0.73)^{(30)}$. Higher scores indicate that foods were obtained very frequently.

\section{Data analysis}

Data were analysed using the SAS statistical software package version $9 \cdot 1$ (SAS Institute Inc., Cary, NC, USA). For all analyses $P=0.05$ was the level of significance. ANOVA was used to compare continuous outcomes across groups of categorical variables and the $t$ test was used to compare continuous outcomes between two groups. Continuous variables used as outcomes were travel time and healthy and unhealthy food-getting scores. For ANOVA analyses, the Bonferroni $t$ test of comparison was used to examine differences between pairs in each group $(\alpha=0 \cdot 05)$. Multiple linear regression analyses were conducted to examine the association of food source and access factors with food-getting outcomes. Dummy variables for food source (corner store $=1 v$. other $=0$ ) and transportation (driving/getting a ride $=1 v$. other $=0$ ) were created. The model included age, gender, household size, residency in Baltimore (East $=1$, West $=0)$, MSL and education $(>12$ years $=1, \leq 12$ years $=0$ ). The naturally log-transformed forms of healthy and unhealthy food-getting scores and MSL were used for regression analyses.

\section{Results}

\section{Description of the study sample}

The study sample included 175 participants, $81 \cdot 1 \%$ of whom were women. The average age was $45 \cdot 7$ (SD 13.6) years with a range of 16-90 years. The average household size was 3.1 (SD 1.7) members with a range of 1-10 members. Respondents had completed an average of $11 \cdot 6$ (SD 1.9) years of school with a range of 5-18 years. The most frequently reported household income category was under \$US $10000 /$ year $(46 \cdot 3 \%)$. Respondents reported working an average of $12 \cdot 7 \mathrm{~h} /$ week in the previous 30 (SD $18.4) \mathrm{d}$ with a range of $0-55 \mathrm{~h}$. Only $38.9 \%$ of the sample reported being employed.

\section{Types of food sources used}

Supermarket shoppers comprised $74.9 \%$ of the sample, whereas $18.3 \%$ of respondents indicated being cornerstore shoppers (Table 1). The supermarkets named most often were a locally owned chain of small supermarkets, whereas $12 \cdot 0 \%$ of respondents named large-chain supermarkets as their main food source. The remainder $(6 \cdot 9 \%)$ indicated that they obtain food primarily from wholesale clubs, indoor or outdoor markets, carry-out and fast-food restaurants, friends and family and from a shelter. 


\section{Reasons for choosing the food source}

The majority of respondents $(53 \cdot 1 \%)$ cited convenience as the main reason for shopping at the chosen food source. Among supermarket shoppers, the three most frequent reasons for choosing this food source were convenience $(51 \cdot 2 \%)$, low cost (19.9\%) and better quality $(16 \cdot 8 \%)$. For corner-store shoppers, the three most frequent reasons were convenience $(65 \cdot 6 \%)$, better quality of foods (16.6\%) and cleanliness/good service $(6 \cdot 25 \%)$. Those who shopped primarily at other food sources also cited convenience as the main reason for choosing that food source $(41 \cdot 7 \%)$, followed by better quality $(25 \cdot 0 \%)$ and lower cost $(16 \cdot 7 \%)$.

\section{Access to food sources}

\section{Transportation to food sources}

Walking was the most frequent form of transportation used for all food sources (Table 2). Respondents indicated driving their own car or getting a ride as the second most frequent form of transportation (30.9\%). Only $8 \%$ of respondents used public transportation (bus or metro) to get to the food source. Walking was the primary form of transportation used by almost all $(97 \cdot 0 \%)$ corner-store shoppers compared with less than half of supermarket shoppers (48.9\%). Among people who drove their own car or had a friend or relative drive, $90 \cdot 7 \%$ were supermarket shoppers whereas $<2 \cdot 0 \%$ were corner-store shoppers.

\section{Time spent travelling to food source}

The mean travel time taken to reach food sources for all respondents was $13 \cdot 3$ (SD 19.4) min. The majority of

Table 1 Food source use among low-income African-American adults in Baltimore City $(n 175)$

\begin{tabular}{lc}
\hline Food source & Most frequent food source $(\%)+$ \\
\hline Supermarket & $74 \cdot 9$ \\
Corner store & $18 \cdot 3$ \\
Indoor or outdoor market & $3 \cdot 4$ \\
Wholesale & $1 \cdot 1$ \\
Carry-out or fast-food restaurants & $1 \cdot 1$ \\
Friends or family & $0 \cdot 57$ \\
Shelter or food pantry or others & 0.57
\end{tabular}

tRespondents reported one food source that they use most often to obtain food. respondents $(82 \cdot 3 \%)$ spent $\leq 15$ min travelling to the main food source. Mean travel time differed significantly by type of food source used and by form of transportation taken (Table 3). Mean travel time among cornerstore shoppers was significantly less than that of supermarket shoppers (Table 3). Both corner-store and supermarket shoppers had a significantly shorter mean travel time compared with those shopping at all other food sources. Comparisons indicated that drivers or those getting a ride, as well as walkers, had a significantly shorter mean travel time compared with those taking the bus or metro (Table 3). Respondents citing convenience as their motivating reason for choosing a food source had the shortest mean travel time $(8.9 \mathrm{~min})$, whereas those citing lower cost had the longest $(14.7 \mathrm{~min})$. However, travel time did not differ significantly by reason for choosing a food source.

\section{Frequency of food source use}

Frequency of shopping varies depending on primary food source. Corner-store shoppers shop most frequently: $75 \%$ of corner-store shoppers shop 5-7 times/week compared with $17 \%$ of supermarket shoppers. The majority of supermarket shoppers (59\%) shop 1 or 2 times/month. Among walkers, $41 \%$ shop 5-7 times/week, compared with $13 \%$ of those taking other forms of transportation.

Table 3 Length of time taken to reach food source on the basis of type of food source and transportation mode

\begin{tabular}{|c|c|c|c|c|}
\hline \multirow[b]{2}{*}{ Category } & \multirow[b]{2}{*}{$n$} & \multicolumn{2}{|c|}{ Travel time (min) } & \multirow[b]{2}{*}{$P$ value* } \\
\hline & & Mean & SD & \\
\hline Food source & & & & $<0.001^{\star *}$ \\
\hline Supermarket & 128 & $11 \cdot 4$ & $9 \cdot 0$ & \\
\hline Corner store & 32 & $5 \cdot 2$ & $5 \cdot 8$ & \\
\hline Others & 11 & $22 \cdot 0$ & $20 \cdot 9$ & \\
\hline Transportation & & & & $0 \cdot 0014^{\star \star \star}$ \\
\hline Walk & 100 & $10 \cdot 0$ & $9 \cdot 7$ & \\
\hline Drive or get a ride & 52 & $10 \cdot 1$ & $7 \cdot 2$ & \\
\hline Bus or metro & 13 & $22 \cdot 2$ & $18 \cdot 3$ & \\
\hline Cab or hack & 4 & $9 \cdot 9$ & $9 \cdot 7$ & \\
\hline Other & 2 & $7 \cdot 0$ & $7 \cdot 1$ & \\
\hline
\end{tabular}

${ }^{*} P$ value for ANOVA with Bonferroni comparisons of means.

${ }^{\star \star} P<0.0167$ is significant for differences in mean travel time between corner stores and both supermarkets and other sources.

${ }^{* * \star} P<0.0125$ is significant for differences in mean travel time between bus or metro and both walking and driving or getting a ride.

Table 2 Types of transportation taken to reach food sources

\begin{tabular}{|c|c|c|c|}
\hline & All shoppers $(n$ 175) & Supermarket shoppers ( $n$ 131) & Corner-store shoppers $(n 32)$ \\
\hline Transportation type & $\%$ & $\%$ & $\%$ \\
\hline Walk & $57 \cdot 1$ & $48 \cdot 9$ & $97 \cdot 0$ \\
\hline Drive own car or ask relative or friend to drive & $30 \cdot 9$ & $37 \cdot 4$ & $3 \cdot 0$ \\
\hline Bus or metro & $8 \cdot 0$ & $8 \cdot 4$ & 0.0 \\
\hline Cab or hack & $2 \cdot 9$ & $3 \cdot 8$ & 0.0 \\
\hline Other or N/A & $1 \cdot 1$ & $1 \cdot 5$ & $0 \cdot 0$ \\
\hline
\end{tabular}

$\mathrm{N} / \mathrm{A}$, not applicable. 
Relationship between food source access and obtaining bealtby and unbealtby food

Regular soda was purchased significantly more frequently in the previous $30 \mathrm{~d}$ by corner-store shoppers (16.7 times) compared with supermarket shoppers $(5 \cdot 6$ times, $P<0 \cdot 0001)$. Potato chips were purchased more frequently by corner-store shoppers $(6.9$ times $)$ compared with supermarket shoppers ( 4.2 times, $P=0 \cdot 05)$. Unhealthy food-getting scores were significantly higher for cornerstore shoppers compared with supermarket shoppers and for walkers compared with those using all other forms of transportation (Table 4). Healthy food-getting scores did not differ significantly by main type of food source or transportation (Table 4). A separate analysis comparing large-chain supermarket shoppers ( $n$ 21) and all other supermarket shoppers ( $n$ 110) found no significant differences in healthy and unhealthy food-getting scores between these two groups. People who shopped almost every day compared with those shopping less frequently had increased unhealthy food-getting scores $(P<0 \cdot 0001)$; however, healthy food-getting scores did not increase with shopping more often $(P=0 \cdot 07$, data not shown).

Given the wide range of ages in the sample, age was categorized into $<40,40-55$ and $>55$ years to assess differences in outcomes by age group. No significant differences in healthy food-getting scores existed by age group. Those aged $<40$ years had significantly higher unhealthy food-getting scores compared with those aged $>55$ years $(P<0 \cdot 016$, data not shown $)$.

Regression analyses showed that corner-store shoppers had significantly higher unhealthy food-getting scores compared with respondents using all other food sources after adjustment for transportation, age, gender, education, household size, MSL and residence (Table 5). Increased household size was associated with higher unhealthy food-getting scores, whereas being female and older age were associated with lower unhealthy foodgetting scores. Driving to the food source was associated with increased healthy food-getting scores after adjusting for type of food source, age, gender, education, household size and residence (Table 5).

\section{Discussion}

The present study provides insight into the relationship between the type of food source used, food source access and food-getting patterns among AA adults in a lowincome urban setting. Although respondents used a variety of food sources, supermarkets and corner stores were most commonly used. Our research shows that choice of food source is associated with the frequency of obtaining unhealthy foods. Corner-store shoppers obtained more unhealthy foods than people shopping at other food sources after controlling for demographic characteristics, transportation and MSL. Regular soda was

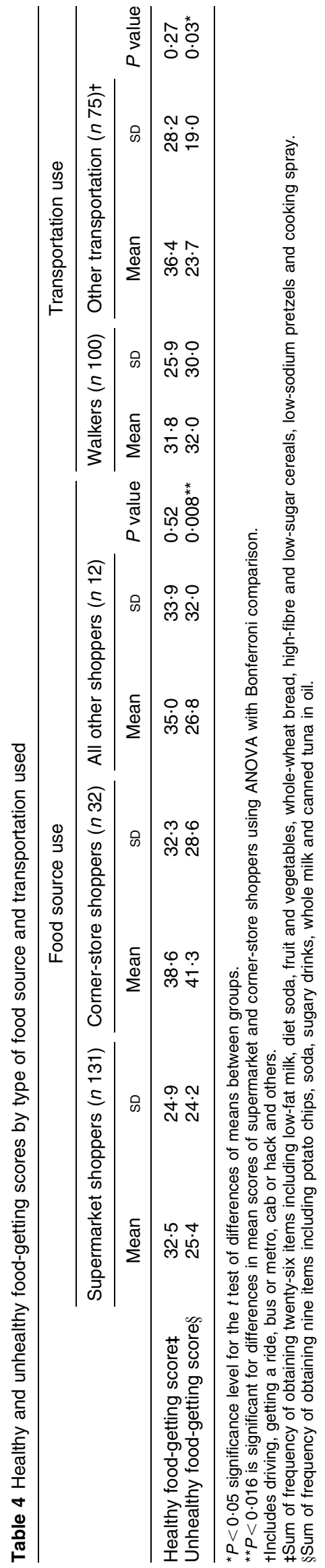


Table 5 Associations from multiple linear regression models for unhealthy and healthy food-getting outcomes

\begin{tabular}{|c|c|c|c|c|}
\hline & \multicolumn{4}{|c|}{ Food-getting outcomes } \\
\hline & \multicolumn{2}{|c|}{ Unhealthy food-getting scoret } & \multicolumn{2}{|c|}{ Healthy food-getting scoreł } \\
\hline & Standardized $\beta$ & $P$ value & Standardized $\beta$ & $P$ value \\
\hline Corner-store shoppers $v$. other shoppers & 0.52 & $0.005^{\star}$ & $0 \cdot 21$ & $0 \cdot 206$ \\
\hline Driving to food source $v$. walking or other transportation & 0.07 & 0.65 & $0 \cdot 34$ & $0 \cdot 012^{*}$ \\
\hline Age (years) & -0.014 & $0.008^{*}$ & -0.003 & 0.59 \\
\hline Sex $($ female $=1, v$. male $=0)$ & $-0 \cdot 38$ & $0 \cdot 026^{*}$ & -0.08 & $0 \cdot 61$ \\
\hline Education ( $>12$ years $v . \leq 12$ years) & $-0 \cdot 19$ & $0 \cdot 25$ & $0 \cdot 21$ & $0 \cdot 17$ \\
\hline Material style of life $(\ln ) \S$ & $-0 \cdot 14$ & 0.24 & $-\|$ & $-\|$ \\
\hline Household size & $0 \cdot 12$ & $0 \cdot 01^{*}$ & 0.06 & $0 \cdot 15$ \\
\hline Residency $($ East Baltimore $=1 \mathrm{v}$. West Baltimore $=0$ ) & 0.08 & 0.55 & $0 \cdot 17$ & $0 \cdot 17$ \\
\hline $\begin{array}{l}n \\
R^{2}\end{array}$ & \multicolumn{2}{|c|}{$\begin{array}{c}166 \\
0 \cdot 21\end{array}$} & \multicolumn{2}{|c|}{$\begin{array}{c}170 \\
0.09\end{array}$} \\
\hline
\end{tabular}

${ }^{\star} P<0.05$ was used as the level of significance.

tSum of frequency of obtaining twenty-six items including low-fat milk, diet soda, fruit and vegetables, whole-wheat bread, high-fibre and low-sugar cereals, low-sodium pretzels and cooking spray (naturally log transformed).

‡Sum of frequency of obtaining nine items including potato chips, soda, sugary drinks, whole milk and canned tuna in oil (naturally log transformed).

\$Material style of life scale was our proxy for socio-economic status and assessed ownership of fourteen different items (e.g. television, cellular phone and central air conditioning) and was natural log transformed.

$\|$ Not included in the model because of poor fit.

by far the most frequently purchased item and was purchased on average almost 4 times/week by corner-store shoppers, with many purchasing soda every day. In general, corner-store shoppers tended to purchase more beverages (e.g. soda, juice and water) and snacks (e.g. potato chips and pretzels) than supermarket shoppers. Proximity to convenience stores has been associated with increased prevalence of overweight and obesity and with higher $\mathrm{BMI}^{(11,31)}$. Considering the high frequency of purchasing sweetened beverages in corner stores, promoting the purchase of bottled water may be an important intervention in corner stores, and substituting water for sweetened beverages has been associated with weight loss over time ${ }^{(32)}$.

We found that corner-store shoppers are more likely to walk to the store and to have the shortest travel time, and that the majority report shopping every day, indicating an association between access and the type of food source used. Transportation access was associated with food-getting patterns. Walking to the food source was associated with obtaining more unhealthy food, whereas being able to drive or have a friend or relative drive was associated with obtaining more healthy food. People who walk to the food source are limited to what is available in their immediate neighbourhood; in Baltimore, lowincome AA neighbourhoods have fewer healthy foods available compared with white high-income neighbourhoods ${ }^{(17)}$. Walking also prohibits an individual from purchasing large amounts of groceries during each trip, requiring more frequent trips. Lacking access to a car may also indicate a lack of economic resources, which may limit the ability to purchase more expensive items, such as fresh fruit and vegetables. People who have access to a car may be able to shop at larger supermarkets outside their immediate neighbourhood, increasing access to healthy food. A study of Food Stamp participants in New Orleans found a positive association between fruit and vegetable consumption and easy access to supermarkets, in which easy access was defined by shopping mainly at a supermarket and either car ownership or a round-trip travel time of $<30 \min ^{(33)}$.

Few people in our study used public transportation and those who did experienced the longest travel times, indicating that adequate public transportation to food sources may be limited. A 2008 study investigating equity in public transit in Baltimore found that people dependent on public transportation experienced problems with infrequent buses, delayed connections and overcrowding, especially in low-income communities ${ }^{(34)}$. As the majority of respondents cited convenience as the motivating reason for choosing a food source, a longer travel time may be a barrier to seeking alternatives to the closest food source in the neighbourhood, a concern that was raised among residents in formative research ${ }^{(35)}$.

Interestingly, after convenience, corner-store shoppers valued better variety and cleanliness and good service when choosing a food source over quality and lower price. Formative research in this population showed that some corner-store shoppers form positive relationships with store owners, which may influence their choice of food source $^{(21)}$. More research into the social dynamics of the neighbourhood corner store is needed to fully understand the motivating reasons for shopping there frequently.

The literature shows that the presence of a supermarket in the neighbourhood increases fruit and vegetable consumption among residents ${ }^{(8-10,33)}$. Our study did not find a significant difference in the purchase of healthy food among corner-store and supermarket shoppers, even though healthy food was rarely bought at corner stores. This may indicate that: (i) corner-store shoppers seek healthy food at the same rate as supermarket shoppers, but use a secondary food source such as a supermarket or indoor market to obtain healthy food; and (ii) the availability 
of healthy foods may be limited in both venues. Research in New Orleans showed that both availability of fruit and vegetables within stores and distance to food stores may predict consumption ${ }^{(9)}$. The majority of supermarket shoppers in Baltimore use small, local supermarkets that tend to have fewer healthy food options compared with larger chain stores $^{(20)}$. Supermarket use alone does not contribute to increased purchases of healthy food, indicating that increased availability or promotion of healthy food may be needed in small neighbourhood supermarkets in Baltimore.

Our findings have implications for interventions in lowincome settings both in the USA and internationally. Studies in Ontario, Canada, found that low-income urban neighbourhoods had fewer supermarkets compared with highincome neighbourhoods and had a large number of variety stores (a food source similar to corner stores), where fresh produce was scarce ${ }^{(36,37)}$. In developed countries outside North America, documented inequalities in food access by neighbourhoods have been less consistent ${ }^{(38)}$. However, increased obesity prevalence among low-income people in developing countries, especially in urban areas, indicates a need to investigate associations between the food environment and food purchases in these settings ${ }^{(39-42)}$. We found that low-income urban corner-store shoppers bought more unhealthy food such as sugar-sweetened beverages and high-fat snacks compared with supermarket shoppers, a finding that may be useful for health promotion in low-income settings internationally, where there has been an influx of cheap, high-energy, low-nutrient food into urban neighbourhoods ${ }^{(43)}$.

There are several limitations to the present study. The first is the use of a convenience sample from supermarkets, corner stores and a community action centre. This sampling strategy was used to recruit AA participants who shopped in food stores in low-income neighbourhoods, but may have led to some sampling bias. In addition, low sample sizes for some variables led to the grouping of variables during analyses. Another limitation of the present study is that psychosocial factors, such as intention and selfefficacy, were not taken into account. These factors may explain some of the variability not accounted for in the regression model for healthy food-getting scores in the present study. Finally, food-getting scores were based on frequency alone and do not account for the quantity and size of items purchased or the amount consumed. More research is needed to examine the direct impact of these factors on diet.

\section{Conclusion}

Access to food sources and the type of food source used are important factors in determining the types of foods that are purchased in this urban low-income AA population. Supermarkets and corner stores are the predominant food sources for low-income AA in Baltimore. The majority of corner-store shoppers report shopping every day and purchase significantly more unhealthy food than supermarket shoppers. In light of this, store interventions are needed to promote healthy food in corner stores and encourage corner-store owners to stock healthy items (e.g. $100 \%$ juice and baked chips). Small supermarkets are also an important venue since almost everyone used supermarkets in the previous month and there is a need for increased availability and promotion of healthy food in these stores. In addition, our study suggests that research on food access and foodpurchasing behaviours may be necessary in international low-income settings where obesity rates are escalating.

Driving or getting a ride to the food source was associated with purchasing more healthy food, whereas walking to the food source was associated with purchasing more unhealthy food. The present study highlights the fact that residents of low-income urban neighbourhoods with access to transportation are turning to food sources outside their immediate neighbourhoods to find adequate healthy food choices. More research is needed to: (i) find ways to increase healthy food availability within walking distance in low-income urban neighbourhoods; and (ii) find effective ways to provide transportation for residents of neighbourhoods that currently have few food sources with healthy food options.

\section{Acknowledgements}

The present research received no specific grant from any funding agency in the public, commercial or not-forprofit sectors. None of the authors have any conflict of interest to declare. H.D.A. developed research questions, conducted data analysis and wrote and prepared the manuscript; J.G. as senior author conceived the study from which these data were taken and provided significant suggestions and comments on the manuscript; S.S. created the scales and provided comments on the manuscript; H.-J.S. and E.S. contributed to instrument development and provided comments on the manuscript.

\section{References}

1. Hedley AA, Ogden CL, Johnson CL et al. (2004) Prevalence of overweight and obesity among US children, adolescents, and adults, 1999-2002. JAMA 291, 2847-2850.

2. Flegal KM, Carroll MD, Ogden CL et al. (2010) Prevalence and trends in obesity among US adults, 1999-2008. JAMA 303, 235-241.

3. Centers for Disease Control and Prevention (2007) National Diabetes Fact Sheet 2007. http://www.cdc.gov/diabetes/ pubs/pdf/ndfs_2007.pdf (accessed February 2010).

4. Marshall MC (2005) Diabetes in African Americans. Postgrad Med J 81, 734-740.

5. Larson NI, Story MT \& Nelson MC (2009) Neighborhood environments: disparities in access to healthy foods in the US. Am J Prev Med 36, 74-81. 
6. Zenk SN, Lachance LL, Schulz AJ et al. (2009) Neighborhood retail food environment and fruit and vegetable intake in a multiethnic urban population. Am J Health Promot 23, 255-264.

7. Zenk SN, Schulz AJ, Israel BA et al. (2006) Fruit and vegetable access differs by community racial composition and socioeconomic position in Detroit, Michigan. Ethn Dis 16, 275-280.

8. Zenk SN, Schulz AJ, Hollis-Neely T et al. (2005) Fruit and vegetable intake in African Americans income and store characteristics. Am J Prev Med 29, 1-9.

9. Bodor JN, Rose D, Farley TA et al. (2008) Neighbourhood fruit and vegetable availability and consumption: the role of small food stores in an urban environment. Public Health Nutr 11, 413-420.

10. Morland K, Wing S \& Diez Roux A (2002) The contextual effect of the local food environment on residents' diets: the atherosclerosis risk in communities study. Am J Public Health 92, 1761-1767.

11. Morland K, Diez Roux AV \& Wing S (2006) Supermarkets, other food stores, and obesity: the atherosclerosis risk in communities study. Am J Prev Med 30, 333-339.

12. Krukowski RA, West DS, Harvey-Berino J et al. (2010) Neighborhood impact on healthy food availability and pricing in food stores. J Community Health 35, 315-320.

13. Moore LV \& Diez Roux AV (2006) Associations of neighborhood characteristics with the location and type of food stores. Am J Public Health 96, 325-331.

14. Galvez MP, Morland K, Raines C et al. (2008) Race and food store availability in an inner-city neighbourhood. Public Health Nutr 11, 624-631.

15. Powell LM, Chaloupka FJ \& Bao Y (2007) The availability of fast-food and full-service restaurants in the United States: associations with neighborhood characteristics. Am J Prev Med 33, Suppl. 4, S240-S245.

16. Powell LM, Slater S, Mirtcheva D et al. (2007) Food store availability and neighborhood characteristics in the United States. Prev Med 44, 189-195.

17. Franco M, Diez-Roux AV, Nettleton JA et al. (2009) Availability of healthy foods and dietary patterns: the Multi-Ethnic Study of Atherosclerosis. Am J Clin Nutr 89, 897-904.

18. Inagami S, Cohen DA, Brown AF et al. (2009) Body mass index, neighborhood fast food and restaurant concentration, and car ownership. J Urban Health 86, 683-695.

19. Li F, Harmer P, Cardinal BJ et al. (2009) Obesity and the built environment: does the density of neighborhood fastfood outlets matter? Am J Health Promot 23, 203-209.

20. Franco M, Diez Roux AV, Glass TA et al. (2008) Neighborhood characteristics and availability of healthy foods in Baltimore. Am J Prev Med 35, 561-567.

21. Gittelsohn J, Franceschini MCT, Rasooly IR et al. (2008) Understanding the food environment in a low-income urban setting: implications for food store interventions. J Hunger Environ Nutr 2, 33-50.

22. Satia JA, Galanko JA \& Siega-Riz AM (2004) Eating at fastfood restaurants is associated with dietary intake, demographic, psychosocial and behavioural factors among African Americans in North Carolina. Public Health Nutr 7, 1089-1096.

23. Wiig K \& Smith C (2009) The art of grocery shopping on a food stamp budget: factors influencing the food choices of low-income women as they try to make ends meet. Public Health Nutr 12, 1726-1734

24. US Census Bureau (2010) State and county quick facts. http:// quickfacts.census.gov/qfd/states/24/24510.html (accessed February 2010).
25. Baltimore Neighborhood Indicators Alliance (2007) Community Statistical Area Profile Baltimore City. http:// www.bniajfi.org/vital_signs_8_report/Baltimore_City.pdf (accessed February 2010)

26. Maryland Family Health Administration (2005) Burden of overweight and obesity in Maryland Report. http://fha. maryland.gov/pdf/cdp/Burden_of_Overweight_Obesity_in Maryland_2005.pdf (accessed February 2010).

27. Sharma S, Cao X, Arcan C et al. (2009) Assessment of dietary intake in an inner-city African American population and development of a quantitative food frequency questionnaire to highlight foods and nutrients for a nutritional invention. Int J Food Sci Nutr 60, Suppl. 5, 155-167.

28. Abell Foundation (2005) In New Orleans, death was highest among people who lacked access to cars. The Abell Report 18, issue 4. Baltimore, MD: The Abell Foundation; available at http://www.abell.org/pubsitems/ arn1105.pdf

29. Waller M (2005) High Cost or High Opportunity Cost? Transportation and Family Economic Success. Brookings Institution Policy Brief no. 35. Washington, DC: The Brookings Institution; available at http://www.brookings. edu/papers/2005/12poverty_waller.aspx

30. Suratkar S, Gittelsohn J, Song HJ et al. (2010) Food insecurity is associated with food-related psychosocial factors and behavior among low-income African American adults in Baltimore City. J Hunger Environ Nutr 5, 100-119.

31. Rose D, Hutchinson PL, Bodor JN et al. (2009) Neighborhood food environments and body mass index: the importance of in-store contents. Am J Prev Med 37, 214-219.

32. Stookey JD, Constant F, Gardner CD et al. (2007) Replacing sweetened caloric beverages with drinking water is associated with lower energy intake. Obesity (Silver Spring) 15, 3013-3022.

33. Rose D \& Richards R (2004) Food store access and household fruit and vegetable use among participants in the US Food Stamp Program. Public Health Nutr 7, 1081-1088.

34. Sen S (2008) Environmental justice in transportation planning and policy: a view from practitioners and other stakeholders in the Baltimore-Washington, D.C metropolitan region. J Urban Technol 15, 117-138.

35. Franceschini MC, Gittelsohn J, Vastine AE et al. (2003) Results of formative research for a food store-based intervention in Baltimore City, Maryland. FASEB J17, A708.

36. Larsen K \& Gilliland J (2008) Mapping the evolution of 'food deserts' in a Canadian city: supermarket accessibility in London, Ontario, 1961-2005. Int J Health Geogr 7, 16.

37. Latham J \& Moffat T (2007) Determinants of variation in food cost and availability in two socioeconomically contrasting neighbourhoods of Hamilton, Ontario, Canada. Health Place 13, 273-287.

38. Cummins S (2005) Food environments and obesity neighbourhood or nation? Int J Epidemiol 35, 100-104.

39. Cummins S \& Macintyre S (2002) 'Food deserts' - evidence and assumption in health policy making. BMJ 325, 436.

40. Monteiro CA, Conde WL, Lu B et al. (2004) Obesity and inequities in health in the developing world. Int $J$ Obes Relat Metab Disord 28, 1181-1186.

41. Uauy R, Albala C \& Kain J (2001) Obesity trends in Latin America: transiting from under- to overweight. J Nutr 131, issue 3, 893S-899S

42. Filozof C, Gonzalez C, Sereday M et al. (2001) Obesity prevalence and trends in Latin-American countries. Obes Rev 2, 99-106.

43. Caballero B (2005) A nutrition paradox - underweight and obesity in developing countries. NEngl J Med 352, 1514-1516. 